\title{
30-days' outcome of haemorrhagic stroke: correlation between intracerebral hemorrhage score and modified Rankin score
}

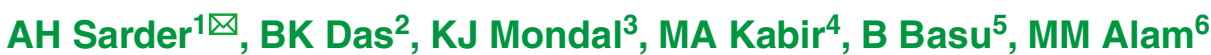

\begin{abstract}
Intracerebral hemorrhage $(\mathrm{ICH})$ constitutes $10 \%$ to $15 \%$ of all strokes. Within 30 days reported mortality is $35-52 \%$ and only $20 \%$ is functionally independent in 6 months. Despite several existing outcome prediction models for $\mathrm{ICH}$, modified Rankin scale is found to be best predictor of outcome in early and long term period. To find out 30-day mortality in $\mathrm{ICH}$ and predict outcome based on modified Rankin score. In this study, 48 patients presenting with acute ICH presenting to a tertiary hospital in Khulna were enrolled. The 30-day mortality and disability were recorded, and $\mathrm{ICH}$ score along with modified Rankin score at presentation were calculated. In this study, the 30 -day mortality rate was $27.1 \%$; regression analysis showed the correlation between the scores (as measured by modified Rankin scale) for patient disability, intraventricular hemorrhage, the Glasgow Coma score, and volume of hematoma ( $>30 \mathrm{ml}$ vs $<30 \mathrm{ml}$ ) were significantly correlated with corresponding $\mathrm{ICH}$ scores. The $\mathrm{ICH}$ scale is a simple clinical grading scale which can predict mortality as well as disability in haemorrhagic stroke within 30 days that can be helpful to physicians in prioritization of their patient management and forecasting about prognosis.
\end{abstract}

Key words: haemorrhagic stroke, 30-days' outcome, ICH score, modified Rankin score, correlation.

\section{Introduction}

Stroke can be defined as sudden developed neurological deficit focal or global, vascular in origin (non-traumatic, non-epileptic) lasting for more than 24 hours or patient dies within this period. There are two types of stroke, ischaemic and haemorrhagic. Stroke is one of the leading causes of death and acquired disability in adult around the world and largest burden for low and middle income countries. $^{1,2}$ A meta-analysis of stroke incidence in high- versus low- and middle-income countries shows that, there is $42.0 \%$ decrease in high-income countries and a greater than $100 \%$ increase in lowand middle-income countries. ${ }^{3}$ Incidence in Bangladesh (2.6 per 1000 population) $)^{4}$ is more than two times of that in the United Kingdom (1.0 per 1000 population) ${ }^{5}$ and Bangladeshi people even after migration to United Kingdom, experience more stroke than the native people.

In Japan, the country with the longest life

1. AH Sarder, Assistant Professor, Department of Neurology, Khulna Medical College, Khulna. Email: drhalimneuro@gmail.com

2. BK Das, Assistant Professor, Department of Neurology, Khulna Medical College, Khulna

3. KJ Mondal, Registrar, Department of Medicine, Khulna Medical College, Khulna

4. MA Kabir, Assistant Professor, Department of Medicine, Gazi Medical College, Khulna

5. B Basu, Professor, Department of Medicine, Gazi Medical College, Khulna

6. MM Alam, Assistant Professor, Department of Neurology, M Abdur Rahim Medical College, Dinajpur 
expectancy from birth, improvements in life expectancy are partially attributed to the large reduction in stroke mortality rates in the 1960s. ${ }^{6}$ Haemorrhagic stroke is defined as bleeding into brain parenchyma without accompanying trauma. It is responsible for $10.0-15.0 \%$ of all stroke and carries higher risk than ischaemic stroke and subarachnoid hemorrhage in terms of mortality and morbidity. ${ }^{7,8}$ Neither surgical hematoma evacuation nor any medical treatment has shown to have undoubted benefit in these patients. $^{9-12}$

Within 30 days reported mortality is 35.0$52.0 \%$ and only $20.0 \%$ is functionally independent in 6 months. ${ }^{13}$ There are several prognostic models for predicting outcome in haemorrhagic stroke but $\mathrm{ICH}$ score is regarded as simple and reliable tool. ${ }^{14-16}$ On the other hand, modified Rankin scale is well validated scoring system to measure stroke disability. ${ }^{17}$

The aim of the present study was to find out 30-day mortality, and the correlation between $\mathrm{ICH}$ score and modified Rankin score.

\section{Materials and Method}

This prospective observational study was carried on admitted haemorrhagic stroke patients in Khulna Medical College Hospital, Khulna from November 2016 to April 2017. All samples purposively selected with voluntary consent from the patients or legal guardians were included in the study. The patients with recurrent stroke, traumatic brain injury and disable prior to stroke, require ventilatory support or surgical intervention were excluded from the study. Total 48 cases were recruited.

$\mathrm{ICH}$ score was calculated after obtaining computed tomography (CT) scan report (Table 1). The volume of haemorrhage was measured by 'ABC/2 $x$ slice thickness' formula in which $A$ is the greatest diameter on the largest hemorrhage slice, $B$ is the diameter perpendicular to $A$, and $C$ is the approximate number of axial slices with hemorrhage multiplied by the slice thickness. Other variables like history of hypertension,
Table 1. Criteria for calculation of $\mathrm{ICH}$ score $^{16}$

\begin{tabular}{lr}
\hline Components & ICH score \\
\hline Age, years & 1 \\
$>80$ & 0 \\
$<80$ & \\
Volume of haem orrhage, $\mathrm{ml}$ & 1 \\
$\quad>30$ & 0 \\
$<30$ & \\
Intraventricular haemorrhage & 1 \\
Yes & 0 \\
No & \\
Infratentorial haemorrhage & 1 \\
Yes & 0 \\
No & \\
Glasgow Coma Score & 2 \\
$3-4$ & 1 \\
$5-12$ & 0 \\
13-15 & $\mathbf{0 - 6}$ \\
\hline Total &
\end{tabular}

Table 2. Modified Rankin scale ${ }^{17}$

\begin{tabular}{|c|c|}
\hline Description & Grade \\
\hline No symptom at all & 0 \\
\hline $\begin{array}{l}\text { No significant disability despite } \\
\text { symptoms; able to carry out all } \\
\text { usual duties and activities }\end{array}$ & 1 \\
\hline $\begin{array}{l}\text { Slight disability; unable to carry } \\
\text { out all previous activities, but } \\
\text { able to look after own affairs } \\
\text { without assistance }\end{array}$ & 2 \\
\hline $\begin{array}{l}\text { Moderate disability; requiring } \\
\text { some help, but able to walk } \\
\text { without assistance }\end{array}$ & 3 \\
\hline $\begin{array}{l}\text { Moderately severe disability; } \\
\text { unable to walk without } \\
\text { assistance and unable to attend } \\
\text { to own bodily needs without } \\
\text { assistance }\end{array}$ & 4 \\
\hline $\begin{array}{l}\text { Severe disability; bedridden, } \\
\text { incontinent and requiring } \\
\text { constant nursing care and } \\
\text { attention }\end{array}$ & 5 \\
\hline Death & 6 \\
\hline
\end{tabular}


diabetes mellitus, smoking, location of hematoma and clinical features were noted. All the patients were treated accordingly and followed up to 30 days, and modified Rankin scpre (Table 2) for disability was measured. Ordinal regression analysis was conducted in different groups (according to $\mathrm{ICH}$ score) with disability to find out its correlation between modified Rankin score and $\mathrm{ICH}$ score.

\section{Results}

The gender and average age of the patients are shown in Table 3 . The number of patients was 48 (23 males and 25 females). The age (mean \pm SD) of the sample was $58.7 \pm 10.9$ years.

Table 4 shows the clinical features of patients. Most of the patients $(60.4 \%)$ had hemiparesis, $18.8 \%$ were unconscious, and $12.5 \%$ were with cerebellar symptom.

Hypertension was present in $60.4 \%$ of the patients, and diabetes mellitus in $56.3 \%$ and $18.8 \%$ patients had both of the conditions. Most common site for intracerebral haemorrhage was basal ganglia (31.3\%) followed by lobe $(25.5 \%)$. Other sites were brainstem, thalamus and cerebellum. Intraventricular

Table 3. Gender and average age of the patients

\begin{tabular}{lrr}
\hline & Number & Mean \pm SD, years \\
\hline Male & 23 & $61.2 \pm 9.6$ \\
Female & 25 & $56.3 \pm 11.7$ \\
\hline Total & $\mathbf{4 8}$ & $\mathbf{5 8 . 7} \pm \mathbf{1 0 . 9}$ \\
\hline
\end{tabular}

haemorrhage was present in $52.1 \%$ of the patients and hematoma below tentorium cerebelli in $29.2 \%$ of the patients.

Table 5 shows the correlation between modified ranking score and corresponding $\mathrm{ICH}$ score. Ordinal regression analysis showed the correlation between the scores (as measured by modified Rankin scale) for patient disability, intraventricular hemorrhage, Glasgow Coma Score (GCS), and volume of hematoma $(>30 \mathrm{ml}$ vs $<30 \mathrm{ml})$ were significantly correlated with corresponding $\mathrm{ICH}$ scores.

The mortality, mean $\pm S D$ volume of haemorrhage, GCS 3-4, GCS 5-12, GCS 13-15 and hospital stay were $27.1 \%, 41.6 \pm 42.3 \mathrm{ml}$, $16.7 \%, 75 \%, 8.3 \%$ and 5.2 days, respectively (data not shown).

\section{Discussion}

The aim of the present study was to evaluate 30-days' outcome in haemorrhagic stroke. The mortality within this period in our study was $27.1 \%$, but other study reported a slightly higher mortality rate, $35-52 \% .{ }^{13}$ In this study, $38.5 \%$ death occurred within 48 hours of stroke onset which is similar to the

Table 4. Clinical features of the patients

\begin{tabular}{lrr}
\hline Symptom & Number & $\%$ \\
\hline Hemiparesis & 29 & 60.4 \\
Unconsciousness & 9 & 18.8 \\
Cerebellar symptom & 6 & 12.5 \\
Hemianaesthesis & 2 & 4.2 \\
Bulber palsy & 2 & 4.2 \\
\hline Total & $\mathbf{4 8}$ & $\mathbf{1 0 0 . 0}$ \\
\hline
\end{tabular}

Table 5. Correlation between modified ranking score and corresponding ICH score

\begin{tabular}{lrr}
\hline Characteristic & $\mathbf{R}^{\mathbf{2}}$ & $p$ value \\
\hline Patient disability & 0.672 & $p<0.01$ \\
Age group (>80 years vs $<80$ years) & 0.046 & $p>0.05$ \\
Intraventricular hemorrhage & 0.289 & $p<0.01$ \\
Glasgow Coma Score & 0.281 & $p<0.01$ \\
Volume of hematoma (>30 $\mathrm{ml}$ vs $<30 \mathrm{ml}$ ) & 0.484 & $p<0.01$ \\
Localization (supratentorial vs infratentorial) & 0.063 & $p>0.05$ \\
\hline
\end{tabular}

$\mathrm{R}$, correlation coefficient. 
study of Mayer et al. ${ }^{18}$ According to some studies, level of consciousness at hospital admission and hematoma volume are the most robust outcome predictors. ${ }^{19}$ We found that those presented with loss of consciousness and hematoma volume $>30 \mathrm{ml}$ had worst prognosis. Although, initial clinical presentation alone cannot always predict functional outcome, because $\mathrm{ICH}$ score is not a static phenomenon, expansion of hematoma detected by repeated CT was found in $27 \%$ of the cases. ${ }^{20}$ Mean age of our study patients was 58.7 years very close to a Malaysian study but another study from Italy showed higher mean age.21,22 The mean duration of hospital stay in the study was 5.2 days, lower than reported in an another study. ${ }^{21}$ Actually, hospital burden and socioeconomic backgrounds were the reasons of the short hospital stay in our study.

Hypertension is the most common significant and independent risk factor for $\mathrm{ICH}$, contributing about $60-70 \%$ of all cases and treatment of hypertension results in reduction in stroke. ${ }^{23,24}$ The mean systolic blood pressure in our patients was found to be 175.7 $\mathrm{mmHg}$, close to other study. ${ }^{21}$ History of diabetes mellitus but not hypertension was reported to be an independent predictor of early death in $\mathrm{ICH}$ patients. ${ }^{25}$ Our study showed opposite effect that history of hypertension but not diabetes had adverse effect on mortality. Smoking was reported as a risk factor for haemorrhagic stroke, ${ }^{26}$ but it did not affect the outcome in our study. Neither age $>65$ years and gender affect the outcome of the patients as reported in a study. ${ }^{27}$ Hematoma volume $>30 \mathrm{ml}$ predicts poor outcome as already proved in other studies. ${ }^{16,21}$ Although site of hematoma was reported to affect outcome, ${ }^{21}$ we did not found any correlation between the site and functional outcomes. Slight disability was found in $20.8 \%$ of the patients, well below from that found in a study of Cheung et al. ${ }^{28}$

To the best of our knowledge, this is the first study to predict 30-days' outcome in haemorrhagic stroke based on ICH score comparing with modified Rankin score. As it is a singlecentered study involving small number of population, a generalized inference based on this study is not suitable to state. Therefore, a multi-centered study with a large sample is needed for further clarification.

\section{Conclusion}

Functional outcome in terms of modified Rankin score well correlated with ICH score which is easy to calculate, might serve as a rapid tool for predicting outcome of haemorrhagic stroke within 30 days that can be helpful to physicians in prioritization of their patient management and forecasting about prognosis.

\section{References}

1. Shi F, Hart RG, Sherman DG, Tegeler $\mathrm{CH}$. Stroke in the People's Republic of China. Stroke 1989;20:1581-5.

2. Murray CJL, Lopez AD, eds. Global Burden of Disease, Vol. 1. Global burden of disease and injury series. Boston: Harvard School of Public Health; 1996.

3. Feigin VL, Lawes CM, Bennett DA, Barker-Collo S, Parag V. Worldwide stroke incidence and early case fatality reported in 56 population-based studies: a systematic review. Lancet Neurol 2009;8:355-69.

4. Bangladesh Bureau of Statistics, 2009. Available from: http://www.bbs.gov.bd/ home.aspx (Accessed on December 15, 2017).

5. Lee S, Shafe ACE, Cowie MR. UK stroke incidence, mortality and cardiovascular risk management 1999-2008: time trend analysis from the General Practice Research Database. BMJ 2011;DOI: 10.1136/bmjopen-2011-000269.

6. Ikeda N, Saito E, Kondo N, et al. What has made the population of Japan healthy? Lancet 2011;378:1094-105.

7. Caplan LR. Intracerebral haemorrhage. Lancet 1992;339:656-8.

8. Broderick JP, Brott T, Tomsick T, Miller R, Huster $\mathrm{G}$. Intracerebral hemorrhage more than twice as common as subarachnoid hemorrhage. J Neurosurg 1993;78:188-91.

9. Auer LM, Deinsberger W, Niederkorn K, et al. Endoscopic surgery versus medical treatment for spontaneous intracerebral hematoma: a randomized study. J Neurosurg 1989;70:530-5. 
10.Juvela S, Heiskanen O, Poranen A, et al. The treatment of spontaneous intracerebral hemorrhage: a prospective randomized trial of surgical and conservative treatment. J Neurosurg 1989;70:755-8.

11. Tellez H, Bauer RB. Dexamethasone as treatment in cerebrovascular disease, I: a controlled study in intracerebral hemorrhage. Stroke 1973;4:541-6.

12.Poungvarin N, Bhoopat W, Viriyavejakul $A$, et al. Effects of dexamethasone in primary supratentorial intracerebral hemorrhage. N Engl J Med 1987;316:1229-33.

13.Andaluz N, Zuccarello M. Recent trends in the treatment of spontaneous intracerebral hemorrhage: analysis of a nationwide inpatient database. J Neurosurg 2009;110:403-10.

14.Broderick JP, Brott TG, Duldner JE, Tomsick T, Huster G. Volume of intracerebral hemorrhage: a powerful and easy-to-use predictor of 30-day mortality. Stroke 1993;24:987-99.

15. Tuhrim S, Dambrosia JM, Price TR, et al. Intracerebral hemorrhage: external validation and extension of a model for prediction of 30-day survival. Ann Neurol 1991;29:658-63.

16. Hemphill JC, Bonovich DC, Besmertis L, Manley GT, Johnston SC. The ICH score: a simple, reliable grading scale for intracerebral hemorrhage. Stroke 2001;32:891-7.

17.Banks JL, Marotta CA. Outcomes validity and reliability of the modified Rankin scale: implications for stroke clinical trials- a literature review and synthesis. Stroke 2007;DOI: 10.1161/01.STR.0000 258355.23810.c6.

18. Mayer SA, Rincon F. Treatment of intracerebral haemorrhage. Lancet Neurol 2005;4:662-72.

19.Savadi-Oskouei D, Sadeghi-Bazargani $H$, Hashemilar M, DeAngelis T. Symptomatologic versus neuroimaging predictors of in-hospital survival after intracerebral haemorrhage. Pak J Biol Sci 2010;13(9):443-7.
20.Broderick JP, Diringer MN, Hill MD, et al. Determinants of intracerebral hemorrhage growth: an exploratory analysis. Stroke 2007;8:1072-5.

21. Rathor MY, Rani MFA, Jamalludin AR, Amran M, Shahrin TCA, Shah A. Prediction of functional outcome in patients with primary intracerebral hemorrhage by clinical-computed tomographic correlations. J Res Med Sci 2012;17(11):1056-62.

22. Colombo A, Faglioni $P$, Marzullo $M$, Scarpa M, Sorgato P. Risk factors and short term prognosis in ischemic and hemorrhagic attacks: review of 503 patients admitted to Neurologic Clinic of Modena. Riv Neurol 1989;59:1-7.

23. Woo D, Sauerbeck LR, Kissela BM, et al. Genetic and environmental risk factors for intracerebral hemorrhage: preliminary results of a population-based study. Stroke 2002;33:1190-6.

24.Collins R, Peto R, MacMahon $S$, et al. Blood pressure, stroke, and coronary heart disease. Part 2, short-term reductions in blood pressure: overview of randomised drug trials in their epidemiological context. Lancet 1990;335:827-38.

25. Tetri S, Juvela $S$, Saloheimo P, Pyhtinen J, Hillbom M. Hypertension and diabetes as predictors of early death after spontaneous intracerebral hemorrhage. $\mathrm{J}$ Neurosurg 2009;110:411-7.

26. Kurth T, Kase CS, Berger K, Gaziano JM, Cook NR, Buring JE. Smoking and risk of hemorrhagic stroke in women. Stroke 2003;34:2792-5.

27.Qureshi AL, Safdar K, Weil J. Predictors of early deterioration and mortality in Black Americans with intracerebral hemorrhage. Stroke 1995;26:1764-7.

28.Cheung RTF, Zou LY. Use of the original, modified, or new intracerebral hemorrhage score to predict mortality and morbidity after intracerebral hemorrhage. Stroke 2003;34:1717-22.

\section{Suggestion for citation of the above:}

Sarder AH, Das BK, Mondal KJ, Kabir MA, Basu B, Alam MM. 30-days' outcome of haemorrhagic stroke: correlation between intracerebral hemorrhage score and modified Rankin score. Mediscope 2018;5(1):10-4. 